\title{
Rosmarinus Officinalis (Rosemary): A Novel Therapeutic Agent for Antioxidant, Antimicrobial, Anticancer, Antidiabetic, Antidepressant, Neuroprotective, Anti- Inflammatory, and Anti-Obesity Treatment
}

\author{
Rafie Hamidpour ${ }^{1 *}$, Soheila Hamidpour ${ }^{2}$ and Grant Elias ${ }^{1}$ \\ ${ }^{1}$ Department of Herbal Medicine, Pars Bioscience Research Center, United States
}

${ }^{2}$ Department of Pathology, University of Kansas City Missouri, United States

${ }^{1}$ Department of Herbal Medicine, Pars Bioscience Research Center, United States

Received: September 07, 2017; Published: September 20, 2017

*Corresponding author: Dr. Rafie Hamidpour, Pars Bioscience, LLC 14109 Cambridge Lane, Leawood, Kansas 66224, United States, Tel: (913)432-0107; Fax: (913)432-5708; E-mail: rafie@parsbioscience.com

\begin{abstract}
Objective: Collect published research articles on the desired topic and summarizes their findings in an evaluation of the preservative and therapeutic potential of Rosmarinus officinalis.

Design: The research articles used in this review were obtained by searching public databases with keywords such as "Rosmarinus officinalis", "R. officinalis" and "rosemary." The articles were then reviewed, summarized, and organized based on topic.

Results: Eighty research articles revealed a wide range of therapeutic applications for Rosmarinus officinalis. Among others, rosemary was found to have antioxidant, antimicrobial, anticancer, anti diabetic, antidepressant, neuro protective, anti-inflammatory, and anti-obesity activities. Rosemary essential oil and extract were found to contain several biologically active compounds. Compared to synthetic agents, Rosmarinus officinalis displayed low toxicity levels and few side effects.

Conclusion: Rosmarinus officinalis shows great promise as a natural food preservative and therapeutic agent in the treatment of many diseases. The chemical composition of rosemary essential oil and extract includes several compounds that are known to be strong antioxidants. Many of the biological properties of rosemary depend on this antioxidant activity. This is especially true in rosemary's anti diabetic and anticancer mechanisms, for oxidative stress is a severe complication in both diseases. The antibacterial, antifungal, and antioxidant activities of rosemary, along with its low toxicity levels, make Rosmarinus officinalis a promising food preservative with fewer side effects than artificial additives. Despite these encouraging findings, more research on the exact mechanisms of rosemary's biological activities is needed before it is consistently used to treat human diseases.
\end{abstract}

Abbreviation: TST: Tail Suspension Test; FST: Forced Swimming Test; AChE: Acetylcholine Cholinesterase; BChE: Butyrylcholinesterase; NGF: Nerve Growth Factor; DGAT: Diacylglycerol Acyltransferase

\section{Introduction}

Rosmarinus officinalis, commonly known as rosemary, is an evergreen perennial shrub belonging to the Lamiaceae family [1]. Native to the Mediterranean region, rosemary is now cultivated around the world due to its use as a natural food preservative and flavoring agent [2]. Rosemary has also been used as a source of traditional medicine for centuries. Its applications have ranged from memory enhancement to the treatment of gastrointestinal diseases $[3,4]$. The secret behind the preservative and therapeutic abilities of rosemary lies in its essential oil and extract. While the chemical composition of these secondary metabolites varies considerably depending on ecological conditions, all rosemary essential oils and extracts contain biologically active compounds that make them unique [5]. For example, phenolic compounds such as carnosic acid, carnosol, and rosemarinic acid are responsible for the strong antioxidant activity of rosemary essential oil and extract [6]. This significant antioxidant activity not only makes rosemary an effective food preservative, but it also accounts for nearly all of rosemary's other therapeutic abilities, including its anticancer and anti diabetic mechanisms [7]. It is therefore the strong antioxidant compounds in its essential oil and extract that is making R. officinalis a plant of great interest in today's food and medical industries. 
Rosmarinus officinalis has been used as a food preservative and flavoring agent for centuries, but only recently have its preservative mechanisms been investigated. Recent studies have displayed rosemary extracts' strong antibacterial, antifungal, and antioxidant activity, all of which combine to make the plant a very effective inhibitor of food pathogens [7-10]. As the public becomes more suspicious of artificial food additives, the demand for safer and more natural preservatives is growing steadily. With few side effects, rosemary has been identified as a natural preservative that could potentially replace artificial additives [10]. Perhaps even more significant than the preservative ability of $\mathrm{R}$. officinalis is its therapeutic potential. Rosemary has been used as a source of traditional medicine since ancient times, but studies have only recently begun to realize its potential contributions to modern medicine.

Remarkably, Rosmarinus officinalis has displayed hepatoprotective, antispasmodic, anticarcinogenic, antitumorigenic, antimicrobial, anti-inflammatory, and antioxidant properties [7]. It has also shown antidiabetic and neuroprotective activities, among others [11]. These biological properties have made rosemary a potential new therapeutic agent in the treatment of many diseases. The purpose of this research article is to review the clinical studies that have demonstrated the preservative and therapeutic potential of Rosmarinus officinalis through the examination of the antioxidant, antimicrobial, anticancer, anti diabetic, antidepressant, neuro protective, anti-inflammatory, and anti-obesity properties of the plant's essential oil and extracts.

\section{Results}

\section{Antioxidant Activity}

The antioxidant activity of Rosmarinus officinalis is welldocumented in the literature reviewed for this project. Indeed, no other biological activity of rosemary was studied more than its antioxidant property. This heightened attention is understandable. Unlike most of its biological activities, Rosemary's antioxidant activity is directly attributable to chemical compounds in the plant's essential oils and extracts. While synergistic mechanisms between many oil components likely contribute to the antioxidant activity, phenolic diterpenes such as carnosic acid, carnosol, and rosemarinic acid have been identified as the strongest antioxidants present in rosemary essential oil $[6,12,13]$.

Rosmarinus Officinalis exerts its antioxidant effect through several metabolic pathways. For example, rosemary essential oil and extract have been shown to destroy and prevent free radicals $[14,15]$. Rosemary is also capable of preventing lipid peroxidation, a destructive process that is caused by oxidative stress $[7,16]$. In addition to reducing the amount of reactive species in the body, rosemary has been found to increase the activity of antioxidant enzymes [17]. All these effects augment the body's defense against harmful reactive species and oxidative damage. Oxidative stress contributes to the development of many diseases. A lack of antioxidant defenses and the resulting oxidative damage have been shown to cause both diabetes and cancer $[18,19]$. By limiting oxidative stress in the body, rosemary helps prevent diseases such as these that depend on the accumulation of free radicals and other reactive species. Therefore, the strong antioxidant activity of $\mathrm{R}$. officinalis is vital to its therapeutic potential. Indeed, its antioxidant activity is fundamental to nearly all of rosemary's other therapeutic applications [7].

\section{Antimicrobial Activity}

Rosmarinus Officinalis has demonstrated potent antibacterial and antifungal activities in multiple studies. Like its antioxidant activity, the antimicrobial activity of rosemary depends on the chemical composition of its essential oil, which can vary greatly depending on location, climate, and time of harvest. The anti microbial activity of oil is also determined by the interactions between its components [5]. Rosemary has been shown to inhibit the growth of bacteria such as Escherichia coli, Listeria monocytogenes, and Staphylococcus aureus $[9,20,21]$. The significance of rosemary's antibacterial effect does not end there, however. According to one study, rosemary has the potential to inhibit the drug resistance of some bacteria by overcoming and reducing the impermeability of these bacteria's membranes [20]. This represents an innovative strategy for containing and eliminating resistant strains of bacteria. Rosemary essential oil can also increase the susceptibility of certain bacteria to standard antibiotics [21]. This impressive antibacterial activity makes R. officinalis a strong defense against common food pathogens and a promising new preservative that could replace artificial additives [10].

In addition to its antibacterial properties, Rosmarinus officinalis has several antifungal mechanisms. The plant's essential oil has been shown to inhibit the adhesion of Candida albicans by denaturing cellular structures and altering membrane permeability [22]. According to one study, rosemary can even prevent the development of highly resistant fungal bio-films. By coating nano particles with rosemary essential oil, a nano bio system was produced that significantly inhibited the adherence and biofilm development of Candida fungal strains [23]. Both these new strategies are necessary alternatives to traditional medicine in the treatment against drug-resistant fungi. The ability to inhibit the growth and aflatoxin production of many fungi contributes to rosemary's potential as an effective food preservative [24].

\section{Anticancer Activity}

Many studies have reported on the anticancer mechanisms of Rosmarinus officinalis. Rosemary has displayed significant anti proliferative activities against several human cancer cell lines. Major compounds in the plant's extract, such as carnosic acid, carnosol, and rosemarinic acid, have been shown to induce apoptosis within these cancer cells, possibly through the production of nitric oxide [19,25-27]. Carnosic acid appears to be the strongest promoter of apoptosis [19,27]. Rosemary extract also has intriguing antitumorigenic activity. In one study, the extract was found to strongly inhibit skin tumorigenesis in mice by preventing carcinogens from binding to epidermal DNA [28]. This anti carcinogenic effect is caused by the extract's antioxidant activity [7]. These anti proliferative and anti tumorigenic activities of R. officinalis can possibly be utilized in future cancer treatments and warrant further investigation. 


\section{Antidiabetic Activity}

Diabetes mellitus is a growing worldwide disorder. By 2025, an estimated 300 million people will be diabetic, and global costs of treating the disease could reach US \$1 trillion annually [18]. The development of diabetes is often fostered by high oxidative stress; pancreatic $\beta$-cells are especially vulnerable to reactive oxygen species, leading to decreased insulin secretion and higher blood glucose levels [18]. This information has prompted new diabetes treatments to focus on natural antioxidants, particularly those found in plants. Not surprisingly, multiple studies have identified Rosmarinus officinalis as a promising anti diabetic agent. Rosemary's antioxidant properties execute several anti diabetic and hypoglycemic mechanisms. In one study, rosemary extract lowered blood glucose levels in normoglycemic, hyperglycemic, and diabetic rabbits. By inhibiting lipid peroxidation and activating antioxidant enzymes, the extract also promoted insulin secretion [18]. Rosemary was also found to alleviate delayed wound healing, a serious complication of diabetes [29]. These anti diabetic activities are attributable to the body's improved antioxidant status after administration of rosemary [30].

\section{Antidepressant Activity}

The potential use of Rosmarinus officinalis as an antidepressant was the focus of many research articles reviewed for this project. The majorities of these studies involved two tests that are used to model antidepressant like effects in mice-the Tail Suspension Test (TST) and Forced Swimming Test (FST). The administration of rosemary continuously decreased the immobility time of mice in both the TST and the FST, indicating an antidepressantlike effect [31-34]. Rosemary's antidepressant potential was further bolstered when it was found to decrease exploratory and anhedonic-like behavior in bulbectomized mice [35]. There is much evidence that the antidepressant activity of R. officinalis depends on interactions with the monoaminergic system. Rosemary is believed to enhance dopaminergic, serotonergic, noradrenergic, and cholinergic functions within the brain, possibly explaining its antidepressant effects [31-33]. Rosemary has also been found to increase the concentration of neurotransmitters in the brains of mice [33]. Several compounds in rosemary extract and essential oil are responsible for its antidepressant activity, including carnosol, betulinic acid, ursolic acid, and polyphenols [31,33,34].

\section{Neuroprotective Activity}

Remarkably, Rosmarinus officinalis has demonstrated significant neuroprotective effects against neurodegenerative diseases such as Alzheimer's disease and dementia. Rosemary has displayed inhibitory activities against the two enzymes in the brain responsible for the breakdown of Acetylcholine-Cholinesterase (AChE) and Butyryl Cholinesterase (BChE). These anti-AChE and anti-BChE activities are likely caused by rosemarinic acid and terpene compounds in the plant's essential oil $[4,36]$. By increasing total choline levels in the brain, rosemary could attenuate not just Alzheimer's disease, but also memory loss, anxiety, and depression $[37,38]$. Two more studies highlight the neuroprotective ability of R. officinalis. In the first, polyphenols present in rosemary extract were found to inhibit stress proteins, which play a role in the neurodegenerative process [39]. The second study concluded that rosemary promotes the production of nerve growth factor (NGF), a protein vital to the growth and maintenance of nerve tissue. Increased NGF levels can help alleviate Alzheimer's disease, dementia, and other neurodegenerative diseases [40]. Both these studies clearly demonstrate rosemary's growing potential as a neuro protective agent.

\section{Anti-Inflammatory Activity}

Rosmarinus officinalis displayed potent anti-inflammatory mechanisms in several of the reviewed studies. Rosemary essential oil and extract were found to significantly inhibitleukocyte migration in vivo [41]. This reduced the number of leukocytes (White Blood Cells) at the site of inflammation, resulting in an anti-inflammatory response [42,43]. Rosemary extract also inhibited other proinflammatory substances, such as nitric oxide and inflammationassociated genes [42-44]. While carnosol and carnosic acid appear to be particularly important, the anti-inflammatory activity of rosemary most likely depends on a synergistic mechanism between many of its components $[41,42,44]$. These studies suggest that the anti-inflammatory effect of R. officinalis is rather strong; in fact, the anti-inflammatory activities of pure carnosol and carnosic acid were found to be nine times higher than that of indomethacin, a common anti-inflammatory drug [42].

\section{Anti-obesity Activity}

While only three studies reported anti-obesity activities of Rosmarinus officinalis, their findings are very noteworthy. All three found rosemary to effectively limit weight gain, but each study identified a different mechanism to explain this response. In one study, extracted carnosic acid was found to suppress adipocyte differentiation. This inhibition of adipogenesis can promote sustainable weight loss [45]. In another study, rosemary extract prevented weight gain by limiting lipid absorption in the intestine. This was made possible through the inhibition of pancreatic lipase activity [46]. Finally, the third study found rosemary extract to inhibit lipid synthesis through the suppression of Diacylglycerol Acyltransferase (DGAT), the main enzyme responsible for the production of triglycerides [47]. The results of all three studies indicate that R. officinalishas great potential as an effective treatment against obesity and other metabolic disorders [45-47].

\section{Discussion}

Rosmarinus officinalis, an evergreen perennial shrub commonly known as rosemary, is garnering considerable attention from the food and medical industries due to its wide array of biological activities. Rosemary has been used as a source of traditional medicine for centuries, but its potential as a natural food preservative has only recently been investigated [4]. Studies have shown that the strong antioxidant and antimicrobial activities of the plant's extracts make rosemary an ideal replacement for more toxic artificial food additives $[9,10]$. As concern over these potentially harmful additives has grown, so has the demand for natural preservatives such as rosemary. While rosemary is beginning to be used as a preservative around the globe, more can be done to maximize the plant's potential. Additional research is needed to 
identify the extracts and essential oils of rosemary that have the most potent preservative activities. Toxicity levels and potential side effects of rosemary must also be constantly monitored. Assuming it remains less toxic, R. officinalis should continue to replace artificial additives in many preservative applications, thereby reducing risk to consumers.

Rosmarinus officinalis has also displayed many intriguing therapeutic properties. Rosemary's antimicrobial, antidepressant, neuro protective, anti-inflammatory, and anti-obesity activities all have potential in the treatment against various diseases. However, it is the anticancer and anti diabetic mechanisms of rosemary that warrant the most attention. Oxidative stress has been shown to contribute to the progression of diabetes mellitus and many forms of cancer [15]. It is not surprising, then, that the strong antioxidant activity of rosemary extract and essential oil represents a promising new strategy in the treatment of both diseases. The plant's ability to promote insulin secretion in diabetic patients and induce apoptosis within cancer cells is particularly intriguing. While these initial results have been encouraging, more clinical studies are needed before rosemary can be regularly used in humans. If it continues to display such promising anti diabetic and anticancer activities with few side effects, R. officinalis could eventually provide an innovative treatment in the fight against these two serious diseases.

\section{Conclusion}

Rosmarinus officinalis (rosemary) has displayed exciting potential as both a natural food preservative and a therapeutic agent in the literature reviewed for this project. The low toxicity levels and strong antioxidant, antibacterial, and antifungal activities of the plant's extract make rosemary an effective food preservative with fewer side effects than artificial additives. The strong antioxidant compounds found in its extract and essential oil account for many of rosemary's biological activities, including its anti diabetic and anticancer mechanisms. Rosemary has also been found to alleviate depression, neurodegenerative diseases, inflammation, and obesity. While the initial results have been encouraging, additional research is needed to confirm the safety and efficacy of R. officinalis as a preservative and therapeutic agent (Figure 1-3).

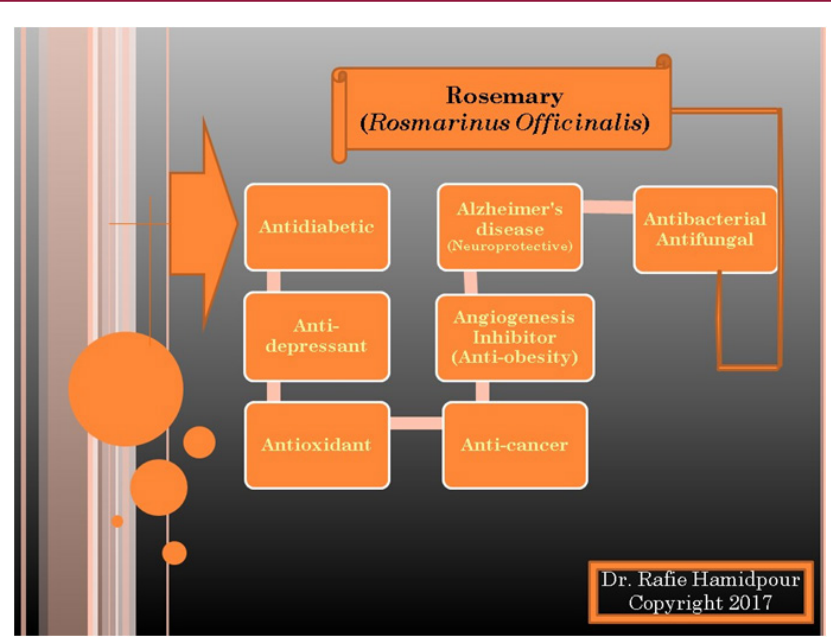

Figure 1: Graphical summary of therapeutic properties.

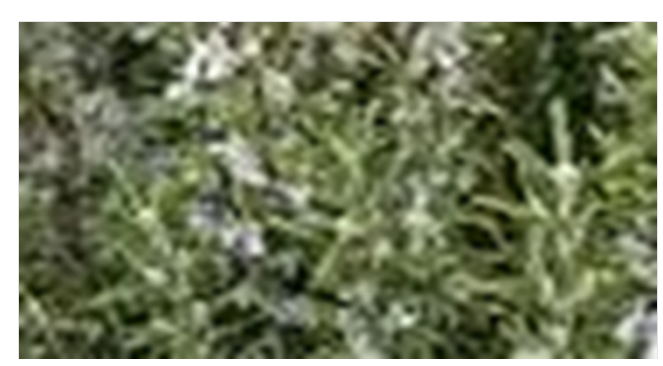

Figure 2: Rosemary Image 1.

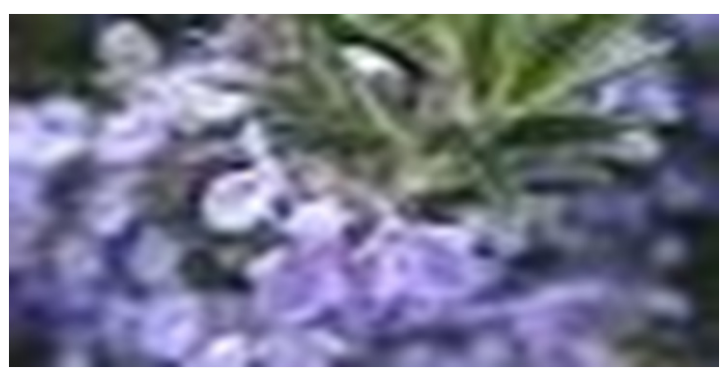

Figure 3: Rosemary Image 2.

\section{Acknowledgment}

Our sincere thanks to Mr. Grant Elias, Summer intern and Student of University of Kansas.

\section{Conflicts of Interest}

The authors declare no conflicts of interest.

\section{References}

1. Hussain AI, Anwar F, Chatha SAS, Jabbar A, Mahboob S, et al. (2010) Rosmarinus officinalis essential oil: antiproliferative, antioxidant and antibacterial activities. Brazilian Journal of Microbiology 41: 1070-1078.

2. Pérez MB, Calderón NL, Croci CA (2007) Radiation-induced enhancement of antioxidant activity in extracts of rosemary (Rosmarinus officinalis L.). Food Chemistry 104: 585-592.

3. Minaiyan M, Ghannadi AR, Afsharipour M, Mahzouni P (2011) Effects of extract and essential oil of Rosmarinus officinalis L. on TNBS-induced colitis in rats. Res Pharm Sci 6(1):13-21.

4. Orhan I, Aslan S, Kartal M, Șener B, Bașer KHC (2008) Inhibitory effect of Turkish Rosmarinus officinalis L. on acetylcholinesterase and butyrylcholinesterase enzymes. Food Chemistry 108(2): 663-668.

5. Jordán MJ, Lax V, Rota MC, Lorán S, Sotomayor JA (2013) Effect of bioclimatic area on the essential oil composition and antibacterial activity of Rosmarinus officinalis L. Food Control 30: 463-468.

6. Yesil-Celiktas O, Nartop P, Gurel A, Bedir E, Vardar Sukan F (2007) Determination of phenolic content and antioxidant activity of extracts obtained from Rosmarinus officinalis' calli. Journal of Plant Physiology 164(11): 1536-1542.

7. Al Sereitia MR, Abu Amerb KM, Sena P (1999) Pharmacology of rosemary (Rosmarinus officinalis Linn.) and its therapeutic potentials. Indian Journal of Experimental Biology 37(2): 124-131.

8. Özcan MM, Chalchat J (2008) Chemical composition and antifungal activity of rosemary (Rosmarinus officinalis L.) oil from Turkey. International Journal of Food Sciences and Nutrition 59(7-8): 691-698.

9. Gachkar L, Yadegari D, Rezaei B, Taghizadeh M, Astaneh SA, et al. (2007) Chemical and biological characteristics of Cuminum cyminum and Rosmarinus officinalis essential oils. Food Chemistry 102(3): 898-904. 
10. Tavassoli SK, Mousavi SM, Emam-Djomeh Z, Razavi SH (2011) Chemical composition and evaluation of antimicrobial properties of Rosmarinus officinalis L. essential oil. African Journal of Biotechnology 10(63): 13895-13899.

11. Faixová Z, Faix S (2008) Biological effects of rosemary essential oil (A Review). Folia Veterinaria 52(3-4): 135-139.

12. Zaouali Y, Bouzaine T, Boussaid M (2010) Essential oils composition in two Rosmarinus officinalis L. varieties and incidence for antimicrobial and antioxidant activities. Food and Chemical Toxicology 48(11): 31443152.

13. Munné-Bosch S, Alegre L, Schwarz K (2010) The formation of phenolic diterpenes in Rosmarinus officinalis L. under Mediterranean climate. Eur Food Res Tehnol 210(4): 263-267.

14.Žegura B, Dobnik D, Niderl MH, Filipič M (2011) Antioxidant and antigenotoxic effects of rosemary (Rosmarinus officinalis L.) extracts in Salmonella typhimurium TA98 and HepG2 cells. Environmental Toxicology and Pharmacology 32: 296-305.

15. Abdel-Wahhab KGE, El-Shamy KA, El-Beih NAE, Morcy FA, Mannaa FAE (2011) Protective effect of a natural herb (Rosmarinus officinalis) against hepatoxicity in male albino rats. Comunicata Scientiae 2(1): 9-17.

16. Bulbul A, Bulbul T, Biricik H, Yesilbag D, Gezen SS (2012) Effects of various levels of rosemary and oregano volatile oil mixture on oxidative stress parameters in quails. African Journal of Biotechnology 11(8): 1800-1805.

17. Afonso MS, Ana Mara de O Silva, Eliane BT Carvalho, Diogo P Rivelli, Sílvia BM Barros, et al. (2013) Phenolic compounds from Rosemary (Rosmarinus officinalis L) attenuate oxidative stress and reduce blood cholesterol concentrations I diet-induced hypercholesterolemic rats. Nutrition \& Metabolism 10: 19.

18. Bakirel T, Bakirel U, Keleş OU, Ülgen SG, Yardibi H (2008) In vivo assessment of antidiabetic and antioxidant activities of rosemary (Rosmarinus officinalis) in alloxan-diabetic rabbits. Journal of Ethnopharmacology 116(1): 64-73.

19. Đilas S, Knez Z, Četojević-Simin D, Tumbas V, Škerget M, et al. (2012) In vitro antioxidant and antiproliferative activity of three rosemary (Rosmarinus officinalis L.) extract formulations. International Journal of Food Science and Technology 47(10): 2052-2062.

20. Oluwatuyi M, Kaatz GW, Gibbons S (2004) Antibacterial and resistance modifying activity of Rosmarinus officinalis. Phytochemistry 65(24): 3249-3254.

21. Marinaş I, Grumezescu AM, Saviuc C, Chifiriuc C, Mihaiescu D, et al. (2012) Rosmarinus officinalis essential oil as antibiotic potentiator against Staphylococcus aureus. Nano Bio Sci 2(1): 271-276.

22. Cavalcanti YW, Leopoldina de F D de Almeida, Wilton Padilha (2011) Anti-adherent activity of Rosmarinus officinalis essential oil on Candida albicans: an SEM analysis. Rev Odonto Cienc 26(2): 139-144.

23. Chifiriuc C, Grumezescu V, Grumezescu AM, Saviuc C, Lazăr V, Andronescu E (2012) Hybrid magnetite nanoparticles/Rosmarinus officinalis essential oil nanobiosystem with antibiofilm activity. Nanoscale Research Letters 10(7): 209.

24. Rasooli I, Fakoor MH, Yadegarinia D, Gachkar L, Allameh A, et al. (2008) Antimycotoxigenic characteristics of Rosmarinus officinalis and Trachyspermum copticum L. essential oils. International Journal of Food Microbiology 122(1-2): 135-139.

25. Kontogianni V, Tomic G, Nikolic I, Nerantzaki AA (2013) Phytochemical profile of Rosmarinus officinalis and Salvia officinalis extracts and correlation to their antioxidant and anti-proliferative activity. Food Chemistry 136(1): 120-129.

26. Tai J, Cheung S, Wu M, Hasman D (2012) Antiproliferation effect of Rosemary (Rosmarinus officinalis) on human ovarian cancer cells in vitro. Phytomedicine 19: 436-443.
27. Petiwala SM, Puthenveetil AG, Johnson JJ (2013) Polyphenols from the Mediterranean herb rosemary (Rosmarinus officinalis) for prostate cancer. Front Pharmacol 4(29).

28. Huang M, Ho C, Wang ZY (1994) Inhibition of Skin Tumorigenesis by Rosemary and Its Constituents Carnosol and Ursolic Acid. Cancer Res 54(3): 701-708.

29. Abu-Al-Basal MA (2010) Healing potential of Rosmarinus officinalis L. on full-thickness excision cutaneous wounds in alloxan-diabetic BALB/c mice. Journal of Ethnopharmacology 131(2): 443-450.

30. Khalil OA, Ramadan KS, Danial EN, Alnahdi HS, Ayaz NO (2012) Antidiabetic activity of Rosmarinus officinalis and its relationship with the antioxidant property. African Journal of Pharmacy and Pharmacology 6(14): 1031-1036.

31. Machado DG, Neis VB, Balen GO, Colla A (2012) Antidepressant-like effect of ursolic acid isolated from Rosmarinus officinalis L. in mice: Evidence for the involvement of the dopaminergic system. Pharmacology, Biochemistry, and Behavior 103(2): 204-211.

32. Machado DG, Bettio LEB, Cunha MP, Capra JC, Dalmarco JB, et al. (2009) Antidepressant-like effect of the extract of Rosmarinus officinalis in mice: Involvement of the monoaminergic system. Progress in NeuroPsychopharmacology \& Biological Psychiatry 33(4): 642-650.

33. Sasaki K, Omri AE, Kondo S, Han J, Isoda H (2013) Rosmarinus officinalis polyphenols produce anti-depressant like effect through monoaminergic and cholinergic functions modulation. Behavioral Brain Research 238: 86-94.

34. Machado DG, Cunha MP, Neis VB, Balen GO, Colla A, et al. (2013) Antidepressant-like effects of fractions, essential oil, carnosol and betulinic acid isolated from Rosmarinus officinalis L. Food Chemistry 136(2): 999-1005.

35. Machado DG, Cunha MP, Neis VB, Balen GO, Colla AR, et al. (2012) Rosmarinus officinalis L. hydroalcoholic extract, similar to fluoxetine, reverses depressive-like behavior without altering learning deficit in olfactory bulbectomized mice. Journal of Ethnopharmacology 143(1): 158-169.

36. Adewusi EA, Moodley N, Steenkamp V (2010) Medicinal plants with cholinesterase inhibitory activity: A Review. African Journal of Biotechnology 9(49): 8257-8276.

37. Ozarowski M, Mikolajczak PL, Bogacz A, Gryszczynska A, Kujawska M, et al. (2013) Rosmarinus officinalis L. leaf extract improves memory impairment and affects acetylcholinesterase and butyrylcholinesterase activities in rat brain. Fitoterapia 91: 261-271.

38. Omri AE, Han J, Yamada P, Kawada K, Abdrabbah MB, et al. (2010) Rosmarinus officinalis polyphenols activate cholinergic activities in PC12 cells through phosphorylation of ERK1/2. Journal of Ethnopharmacology 131(2): 451-458.

39. Omri AEL, Han J, Abdrabbah MB, Isoda H, et al. (2012) Down regulation effect of Rosmarinus officinalis polyphenols on cellular stress proteins in rat pheochromocytoma PC12 cells. Cytotechnology 64(3): 231-240.

40. Kosaka K, Yokor T (2003) Carnosic Acid, a Component of Rosemary (Rosmarinus officinalis L.), Promotes Synthesis of Nerve Growth Factor in T98G Human Glioblastoma Cells. Biol Pharm Bull 26(11): 1620-1622.

41. De Melo GAN, Grespan R, Fonseca JP, Farinha TO, et al. (2011) Rosmarinus officinalis L. Essential Oil Inhibits In Vivo and In Vitro Leukocyte Migration. Journal of Medicinal Food 14(9): 944-949.

42. Mengoni ES, Vichera G, Rigano LA, Rodriguez-Puebla ML, et al. (2011) Suppression of COX-2, IL- $1 \beta$ and TNF- $\alpha$ expression and leukocyte infiltration in inflamed skin by bioactive compounds from Rosmarinus officinalis L. Fitoterapia 82(3): 414-421.

43. Benincá JP, Dalmarco JB, Pizzolatti MG, Fröde TS (2011) Analysis of the anti-inflammatory properties of Rosmarinus officinalis L. in mice. Food Chemistry 124: 468-475. 
44. Yu M, Choi J, Chae I, Im I, Im H, et al. (2013) Suppression of LPS-induced inflammatory activities by Rosmarinus officinalis L. Food Chemistry 136(2): 1047-1054.

45. Gaya M, Repetto V, Toneatto J, Anesini C, Piwien-Pilipuk G, et al. (2013) Antiadipogenic effect of carnosic acid, a natural compound present in Rosmarinus officinalis, is exerted through the C/EBPs and PPAR $\gamma$ pathways at the onset of the differentiation program. Biochimica et Biophysica Acta 1830(6): 3796-3806.
46. Ibarra A, Cases J, Roller M, Chiralt-Boix A, Coussaert A, et al. (2011) Carnosic acid-rich rosemary (Rosmarinus officinalis L.) leaf extract limits weight gain and improves cholesterol levels and glycaemia in mice on a high-fat diet. British Journal of Nutrition 106(8): 1182-1189.

47. Cui L, Kim MO, Seo JH, Kim IS, Kim NY, et al. (2012) Abietane diterpenoids of Rosmarinus officinalis and their diacylglycerol acyltransferaseinhibitory activity. Food Chemistry 132(4): 1775-1780.

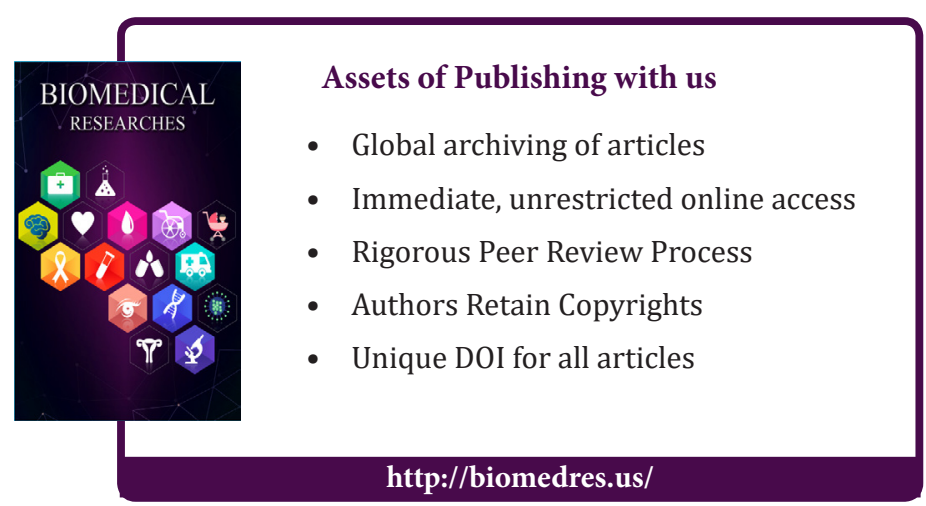

